\title{
FORECASTING THE SALES OF CONSOLE GAMES FOR THE ITALIAN MARKET
}

\author{
Renato Rossetti \\ Ubisoft S.p.A., Milan, Italy \\ e-mail: renatorossetti60@hotmail.com \\ ORCID: 0000-0003-1897-309X \\ (C) 2019 Renato Rossetti \\ This is an open access article distributed under the Creative Commons Attribution-NonCommercial- \\ NoDerivs license (http://creativecommons.org/licenses/by-nc-nd/3.0/)
}

DOI: 10.15611/eada.2019.3.07

\begin{abstract}
In videogames industry, time series analysis can be very useful in determining the general evolution and behaviour of the market dynamics. These methods are applicable to any time series forecasting problem, regardless of the application sector. This article discusses time series approaches to forecast the sales of console games for the Italian market. In particular two univariate techniques were evaluated, exponential smoothing and the SARIMA technique. The aim is to exploit the capabilities of these statistical methods in order to have a comparison of the results and to choose the most accurate model through an ex-post evaluation. Using monthly time-series data from November 2005 to September 2017, the selection of the most suitable model was indicated by the smallest value of the measures of accuracy (MAPE, sMAPE, RMSE) for the out-of-sample observations regarding the period October 2017-September 2018. The implementation of the models was done using Forecast PRO and Gretl. The time series involved is related to the sales regarding the first party manufacturers of consoles and handhelds (Microsoft, Sony and Nintendo).
\end{abstract}

Keywords: exponential smoothing, SARIMA, forecast, videogames.

\section{Introduction}

There is a constant need regarding the demand forecasting. Given the strong seasonal nature and the marked fluctuations due to technological innovation and pricing policy, predicting the evolution of a particular business which follows some dynamics, is a crucial aspect in order to identify the appropriate and specific model able to encompass all the features and peculiarities of the market. Furthermore, successful planning of the devices allows the manufacturers to shape more accurate production planning. In this paper two statistical models were applied, exponential smoothing and the SARIMA model, and the goal is to predict the most accurate values of console games for 12 months ahead with the use of ex-post analysis. Moreover, the market is also affected by the games genres and by the game-players 
attitude, and additionally by some external conditions. This article consists of four sections:

- The methodology used and a brief description of the measures of the loss function.

- The monthly dataset.

- Results.

- Concluding remarks.

The forecasting models were developed using the first 1 to 12 observations, where 1 is the length of the series. This period is normally set by the production planning and decision-making, and another reason is due to yearly seasonality. Then, 12 forecasts values were produced for each model and their accuracy was evaluated compared to the actual values not used in developing the forecasting models. The first approach is based on the exponential smoothing methods and is derived from the work by Kalman [1960]. Exponential smoothing, or ETS, are the common methods of forecasting, mainly due to the very simple concept and minimal computation. Furthermore, ETS methods are also very flexible and they are supported by several analysis and practical applications [Hibon, Makridakis 1979]. The second approach is based on the Box Jenkins procedure, [Box et al. 1994] where it is supposed that the time series is stationary. In order to do that, Box and Jenkins recommend differentiating non-stationary time series, one or more times, to achieve stationarity. The approach is based on the combination of autoregressive and moving average parameters. The classification of this model is called ARIMA, or SARIMA if the seasonal part of the model is included. The methods are evaluated for short-term forecasting horizons.

\section{Methodology}

The most popular methods in the univariate modelling technique are represented by exponential smoothing and SARIMA techniques. The forecast for exponential smoothing is obtained as the weighted average of previously observed values where the weights decline exponentially, then the recent observations concur to the forecast more than the values of earlier observations [Office for National Statistics, 2008]. In particular the Holt-Winters method with damped trend was used. Damped trend is very important for forecasting properties, as confirmed by Gardner (2006) and the importance of using damped trend is recognized e.g. by Hyndman, Koelher, Ord and Snyder [2008]. The characteristics and flexibility of the model were described by Gardner and McKenzie [2011]. The assumption regarding the SARIMA model is related to the fact that the observed values depends on the linear combination of previously observed values. The advantage of the SARIMA model is due to the model building and the process used for accepting or rejecting the parameters after the diagnostic checking. Another feature is flexibility in case the representation is only for the AR part or the MA part or the combination (ARMA); for this class of 
models the limitation is due to the linear hypothesis of the time series Zangh [2001]. Both the methods are used for monthly data.

\subsection{Simple exponential smoothing}

The general form of simple exponential smoothing [Brown 1959], is given by:

$$
\begin{gathered}
F_{t}=\alpha z_{t}+(1-\alpha) F_{t-1}, \\
\hat{z}_{t}(l)=F_{t},
\end{gathered}
$$

where $z_{t}$ is the actual value in period $t, F$ is the level at time $t, \alpha$ is the smoothing coefficient taking values in the interval $(0,1]$ and $\hat{z}_{t}(l)$ the $l$ step ahead forecast at period $t$. The corresponding forecast error is given by:

whereas

$$
e_{t}(l)=z_{t}(l)-\hat{z}_{t}(l)=z_{t}(l)-F_{t}
$$

$$
e_{t}=z_{t}-\hat{z}_{t-1}=z_{t}-F_{t-1} .
$$

Then, from (1) we have:

$$
F_{t}=F_{t-1}+\alpha e_{t} .
$$

By successive substitution, this equation becomes:

$$
F_{t}=\alpha \sum_{i=0}^{\infty}(1-\alpha)^{i} z_{t-1}
$$

which is simple exponential smoothing (SES).

\subsection{Holt's method}

Another contribution is given by Holt [1957] where the estimation is:

$$
F_{t}=\alpha z_{t}+(1-\alpha)+\left(F_{t-1}-T_{t-1}\right),
$$

where $T_{t-1}$ and $T_{t}$ is the Trend at time $t-1$ and $t$. Then,

$$
T_{t}=\beta\left(F_{t}-F_{t-1}\right)+(1-\beta) T_{t-1},
$$

where $\alpha$ is the smoothing coefficient for the level and $\beta$ is the smoothing coefficient for the trend in the interval $(0,1]$.

Then, the $l$ step ahead forecast is given by:

$$
\hat{z}_{t}(l)=F_{t}+l T_{t} .
$$

As we can see, Holt's method is using different constants for local level and trend. 


\subsection{The Holt-Winters method}

This method is based on Holt's calculation with the additional term introduced by Winters [1960] related to the seasonal evaluation. The general equation is then:

$$
\begin{gathered}
F_{t}=\alpha\left(z_{t}-I_{t-p}\right)+(1-\alpha)\left(F_{t-1}+T_{t-1}\right), \\
T_{t}=\beta\left(F_{t}-F_{t-1}\right)+(1-\beta) T_{t-1}, \\
I_{t}=\gamma\left(z_{t}-F_{t}\right)+(1-\gamma) I_{t-p}, \\
\hat{z}_{t}(l)=F_{t}+l T_{t}+I_{t-p+m},
\end{gathered}
$$

where $z_{t}$ is the time series in period $t, F_{t}$ is the level, $I_{t}$ and $I_{t-p}$ are the seasonal indicators at time $t$ and $t-p ; \alpha, \beta$ and $\gamma$ are the smoothing coefficients for level, trend and seasonality. Position $p$ refers to the length of a complete seasonal cycle. $\hat{z}_{t}(l)$ represents the smoothed forecast from the origin to lead time.

Another version is the Holt-Winters method with damped trend: this method has been modified by Gardner and McKenzie [1985] in order to gain more controls on the trend extrapolation. The equation of damped form is written as:

$$
\begin{gathered}
F_{t}=\alpha\left(z_{t}-I_{t-p}\right)+(1-\alpha)\left(F_{t-1}+\delta T_{t-1}\right), \\
T_{t}=\beta\left(F_{t}-F_{t-1}\right)+(1-\beta) \delta T_{t-1}, \\
I_{t}=\gamma\left(z_{t}-F_{t}\right)+(1-\gamma) I_{t-p}, \\
\hat{z}_{t}(l)=F_{t}+\sum_{i=1}^{m} \delta^{i} T_{t}+I_{t-p+m},
\end{gathered}
$$

where $z_{t}$ is the time series in period $t, F_{t}$ is the level, $I_{t}$ and $I_{t-p}$ are the seasonal indicators at time $t$ and $t-p$ and $\alpha, \beta$ and $\gamma$ are the smoothing coefficients for level, trend and seasonality and $\delta$ is the dampening coefficient. $\hat{z}_{t}(l)$ represents the smoothed forecast from the origin to lead time $l$.

\subsection{The SARIMA method}

Box and Jenkins proposed a complete process where the main steps are:

1. Identification. At this stage the potential model is proposed after a preliminary transformation and stationary conditions have been achieved.

2. Estimation and diagnostic. After the identification, the parameters of the SARIMA model are estimated and submitted for the diagnostic process.

3. Forecasting. The final aim of the process is to produce out-of-sample forecasted observations based on the training set. The forecast is provided with the confidence interval. 
In order to detect stationarity and seasonality, the autocorrelation and partial autocorrelation plot are used. Once these aspects have been addressed, the next process is to identify the appropriate orders of parameters $p, q$ and $P, Q$. The general equation is

$$
\Phi\left(B^{s}\right) \nabla_{s}^{D} z_{t}=\Theta\left(B^{s}\right) \alpha_{t},
$$

where $s=12$ and $\nabla_{s}=1-B^{S}$ and $\Phi\left(B^{S}\right)$ and $\Theta\left(B^{S}\right)$ are polinomyals of orders $P$ and $Q$. The equation that links errors $\alpha_{t}$ with equation (18), is given by

$$
\phi(B) \nabla^{d} \alpha_{t}=\theta(B) a_{t},
$$

where $a_{i}$ is the white process and $\phi(B)$ and $\theta(B)$ are polynomials in $B$ of degrees $p$ and $q$ respectively. Substituting (19) in (18), we obtain a multiplicative model:

$$
\phi_{p}(B) \Phi_{P}\left(B^{s}\right) \nabla^{d} \nabla_{s}^{D} z_{t}=\theta_{q}(B) \Theta_{Q}\left(B^{s}\right) a_{t} .
$$

Then the resulting process is said to be of the $\operatorname{order}(p, d, q) \times(P, D, Q)$.

The forecast for lead time $l$, is given by:

$$
\hat{z}_{t}(l)=\psi_{l}^{*} a_{t}+\psi_{l+1}^{*} a_{t-1}+\psi_{l+2}^{*} a_{t-2}+\ldots
$$

where $\psi_{j}^{*}$ are to be determined. The mean square error of the forecast is

$$
E\left[z_{t+l}-\hat{z}_{t}(l)\right]^{2}=\left(1+\psi_{1}^{2}+\psi_{2}^{2}+\ldots+\psi_{l-1}^{2}\right) \sigma_{a}^{2}+\sum_{j=0}^{\infty}\left(\psi_{l+j}-\psi_{l+j}^{*}\right)^{2} \sigma_{a}^{2}
$$

which is minimized by setting:

$$
\psi_{l+j}-\psi_{l+j}^{*}=0 .
$$

Thus we have,

$$
z_{t+l}=\left(a_{t+l}+\psi_{1} a_{t+l-1}+\ldots+\psi_{l-1} a_{t+1}\right)+\left(\psi_{l} a_{t}+\psi_{l+1} a_{t-1}+\ldots\right)=e_{t}(l)+\hat{z}_{t}(l)
$$

and the variance of the forecast error is:

$$
V(l)=\operatorname{Var}\left[e_{t}(l)\right]=\left(1+\psi_{1}^{2}+\psi_{2}^{2}+\ldots+\psi_{l-1}^{2}\right) \sigma_{a}^{2} .
$$

Then, from a difference equation form we have

$$
\begin{aligned}
& {\left[z_{t+l}\right]=z_{t}(l)=\varphi_{1}\left[z_{t+l-1}\right]+\ldots+\varphi_{p+d}\left[z_{t+l-p-d}\right]-\theta_{1}\left[a_{t+l-1}\right]-} \\
& \ldots-\theta_{q}\left[a_{t+l-q}\right]+\left[a_{t+l}\right] .
\end{aligned}
$$

Then the variance is:

$$
V(l)=\left(1+\sum_{J=1}^{l-1} \psi_{j}^{2}\right) \sigma_{a}^{2}
$$


where the prediction interval is given by:

$$
z_{t+l}( \pm)=\hat{z}_{t}(l) \pm u_{\frac{\varepsilon}{2}}\left(1+\sum_{J=1}^{l-1} \psi_{j}^{2}\right)^{1 / 2} s_{a}
$$

\subsection{Measuring forecast error}

After the model is identified and specified, its performance should be compared with the historical data. The most common indicators of loss function are MAPE (Mean Absolute Percentage Error) and sMAPE (symmetric Mean Absolute Percentage Error), according to Armstrong [1985]:

$$
\begin{gathered}
\text { MAPE }=\frac{1}{n} \sum_{t=1}^{n}\left|\frac{z_{t}(l)-\hat{z}_{t}(l)}{z_{t}(l)}\right| 100, \\
\operatorname{sMAPE}=\frac{1}{n} \sum_{t=1}^{n} \frac{\left|z_{t}(l)-\hat{z}_{t}(l)\right|}{\left(\left|z_{t}(l)\right|+\left|\hat{z}_{t}(l)\right|\right) / 2} 100 .
\end{gathered}
$$

Another measure of accuracy is given by RMSE (Root Mean Squared Error)0

$$
\mathrm{RMSE}=\sqrt{\frac{\left(z_{t}(l)-\hat{z}_{t}(l)\right)^{2}}{N}}
$$

\section{Empirical analysis}

\subsection{The Dataset}

TOTAL CONSOLES

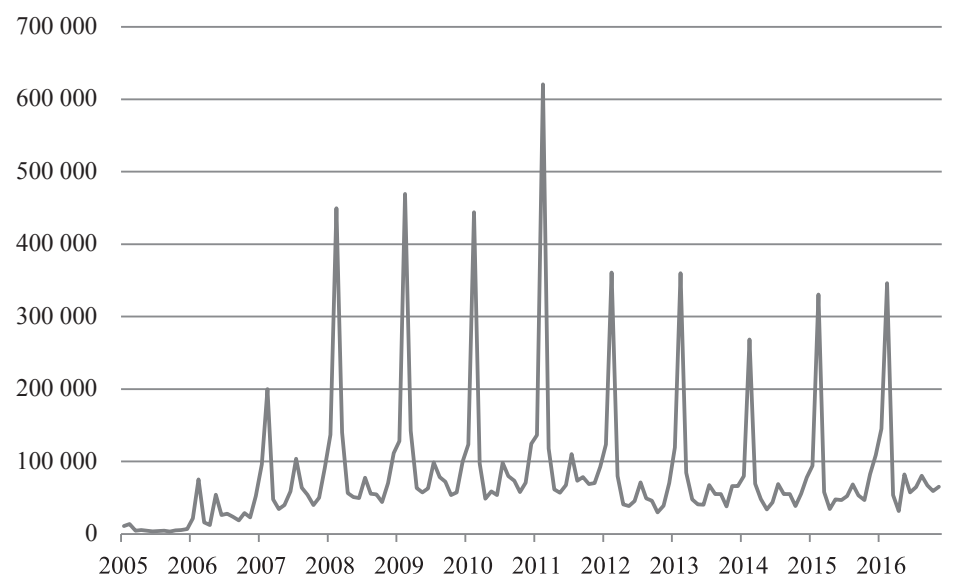

Fig. 1. Dataset for consoles between November 2005 and September 2017 Source: Ubisoft Italy. 
The dataset consists of 143 observations between November 2005 and September 2017. No specification by manufacturer or breakdown by platform game has been included. The data is related to the aggregation of the console games and handhelds provided by the three main producers (Microsoft, Sony and Nintendo) in the above mentioned period. The graphic representation, (Figure 1) shows a remarkable seasonality corresponding to the month of December in each year.

\section{Results}

\subsection{Holt-Winters exponential smoothing with damped trend}

Following the method with damped trend, the parameters were: $\alpha=0.1029$, $\beta=0.0253, \gamma=0.8981$ and $\delta=0.9818$. It is clear that parameter $\alpha$ can assume values between 0 and 1. If $\alpha$ is zero, a constant unchanging seasonal component is used to generate the one-step-ahead forecasts. If the $\alpha$ parameter is equal to 1 , then the seasonal component is modified "maximally" at every step of the forecast procedure. The outcome using this process is reported in Table 1 and in Figure 2.

Table 1. Comparison between the actual data and the exponential smoothing forecast with additive damped trend.

\begin{tabular}{|c|c|c|}
\hline Period & Actual & $\begin{array}{c}\text { Forecast } \\
\text { (Exp. Smoothing Damped Trend) }\end{array}$ \\
\hline Oct-17 & 78.319 & 111.203 \\
\hline Nov-17 & 196.358 & 140.886 \\
\hline Dec-17 & 309.692 & 343.317 \\
\hline Jan-18 & 58.297 & 55.237 \\
\hline Feb-18 & 43.646 & 34.614 \\
\hline Mar-18 & 48.974 & 78.477 \\
\hline Apr-18 & 54.708 & 56.246 \\
\hline May-18 & 62.360 & 64.133 \\
\hline Jun-18 & 81.477 & 79.367 \\
\hline Jul-18 & 59.154 & 65.761 \\
\hline Aug-18 & 50.182 & 57.672 \\
\hline Sep-18 & 80.697 & 68.650 \\
\hline
\end{tabular}

Source: Actual Data: Ubisoft Italy; Forecast Exp Smooth. Damp. Trend: Forecast Pro Soft. 


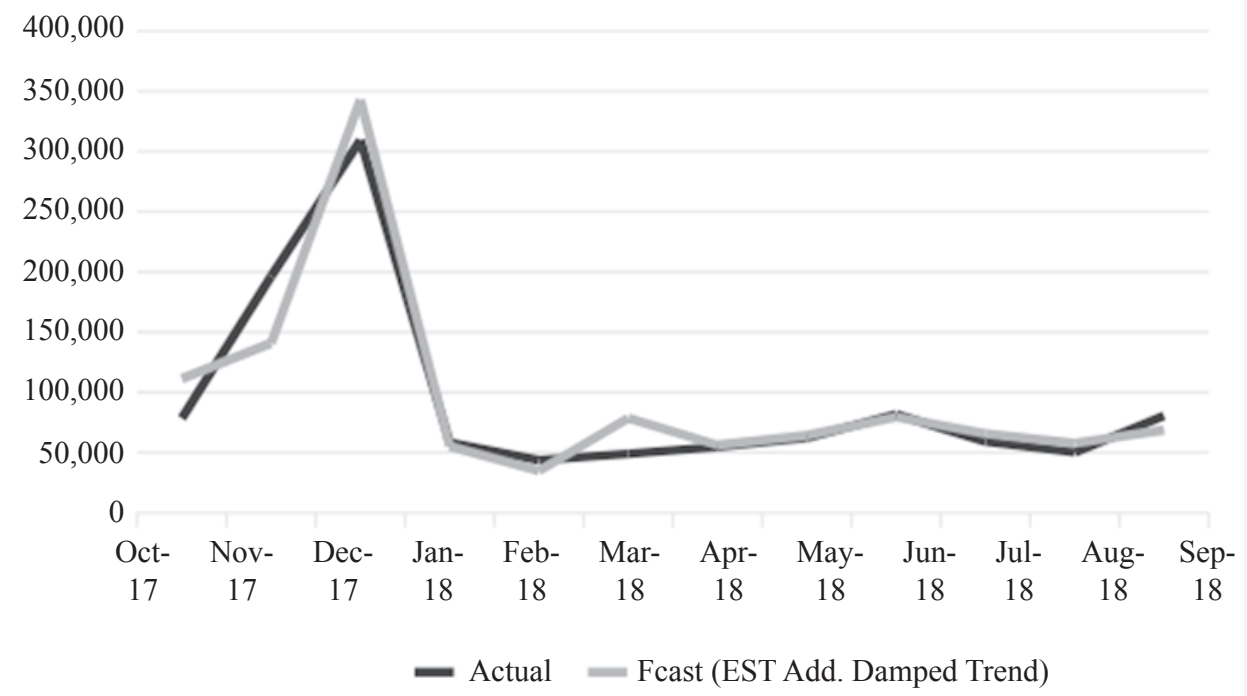

Fig. 2. Comparison between actual data and forecast line using exponential smoothing with damped trend parameter

Source: Actual Data: Ubisoft Italy; Forecast EST Damp. Trend: Forecast Pro Soft.

\subsection{The SARIMA model}

From the data presented in Figure 1, a logarithm transformation is appropriated in order to obtain a more homogenous variance of the series. Each value in the series is substituted with its natural logarithm, and then a reverse of the logarithms of the single values is applied at the end of the process. At the identification stage, the goal is to detect seasonality and the order of the autoregressive and moving average parameters. The AR and MA parameters were identified by the autocorrelation and partial autocorrelation function. The diagnostic check for the model is given by the traditional measures of accuracy such as the Akaike Information Criteria [Akaike 1974], BIC [Schwarz 1978], and HQC [Hannan, Quinn 1979], while the prediction performance was provided by the loss function such as MAPE, SMAPE and RMSE. In this case SARIMA 2,1,0 (1,1,0) $)_{12}$ was chosen. Table 2 and Figure 3 report and summarize the result of the application. 
Table 2. Comparison between the actual data and the SARIMA 2,1,0 $(1,1,0)_{12}$ forecast

\begin{tabular}{|c|c|c|}
\hline Period & Actual & $\begin{array}{c}\text { Forecast } \\
\text { SARIMA }(2,1,0)(1,1,0)_{12}\end{array}$ \\
\hline Oct-17 & 78.319 & 96.096 \\
\hline Nov-17 & 196.358 & 132.815 \\
\hline Dec-17 & 309.692 & 345.977 \\
\hline Jan-18 & 58.297 & 55.582 \\
\hline Feb-18 & 43.646 & 33.444 \\
\hline Mar-18 & 48.974 & 64.486 \\
\hline Apr-18 & 54.708 & 51.244 \\
\hline May-18 & 62.360 & 57.271 \\
\hline Jun-18 & 81.477 & 71.849 \\
\hline Jul-18 & 59.154 & 57.290 \\
\hline Aug-18 & 50.182 & 49.733 \\
\hline Sep-18 & 80.697 & 66.882 \\
\hline
\end{tabular}

Source: Actual Data: Ubisoft Italy; Forecast SARIMA $(2,1,0)(1,1,0)_{12}$ : GRETL Soft.

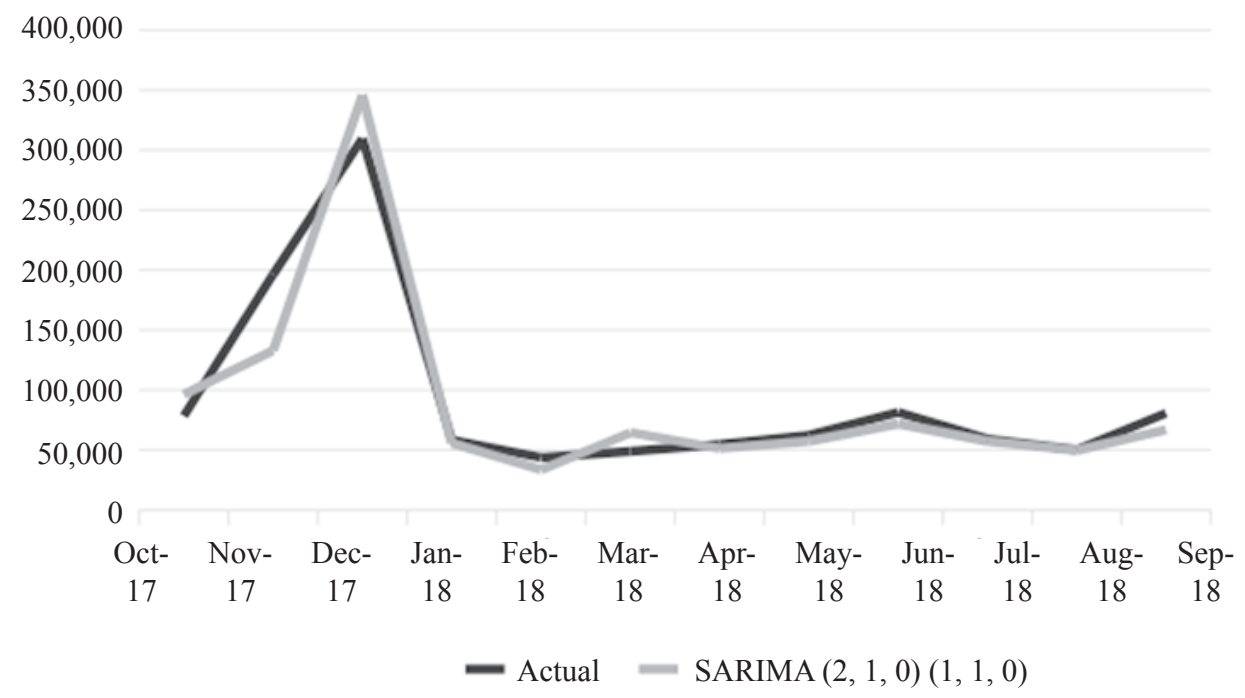

Fig. 3. Comparison between actual data and forecast line using the SARIMA model $(2,1,0)(1,1,0)_{12}$ Source: Actual Data: Ubisoft Italy; Forecast SARIMA: GRETL Soft.

\subsection{Evaluation of the two approaches}

The primary aim and the purpose of this paper was to evaluate, for this market, the use and capabilities of two univariate techniques, exponential smoothing and the SARIMA technique. Based on the chosen models, the performance of the two 
models was evaluated in terms of accuracy. The accuracy of time series is a crucial aspect for many decision-making problems and the measures of accuracy are expressed by MAPE, sMAPE and RMSE related to an ex-post analysis on the last 12 months. Below in Table 3, the performances for these methods based on the measures are proposed.

Table 3. Proposed measures of accuracy of the methods

\begin{tabular}{|l|c|c|c|}
\hline & MAPE & SMAPE & RMSE \\
\hline ETS & 0.180 & 0.110 & 23.283 \\
\hline SARIMA & 0.145 & 0.101 & 22.999 \\
\hline
\end{tabular}

Source: ETS: Forecast Pro Soft. SARIMA $(2,1,0)(1,1,0)_{12}$ : GRETL Soft.

\section{Actual-Forecast Lower and Upper Limit}

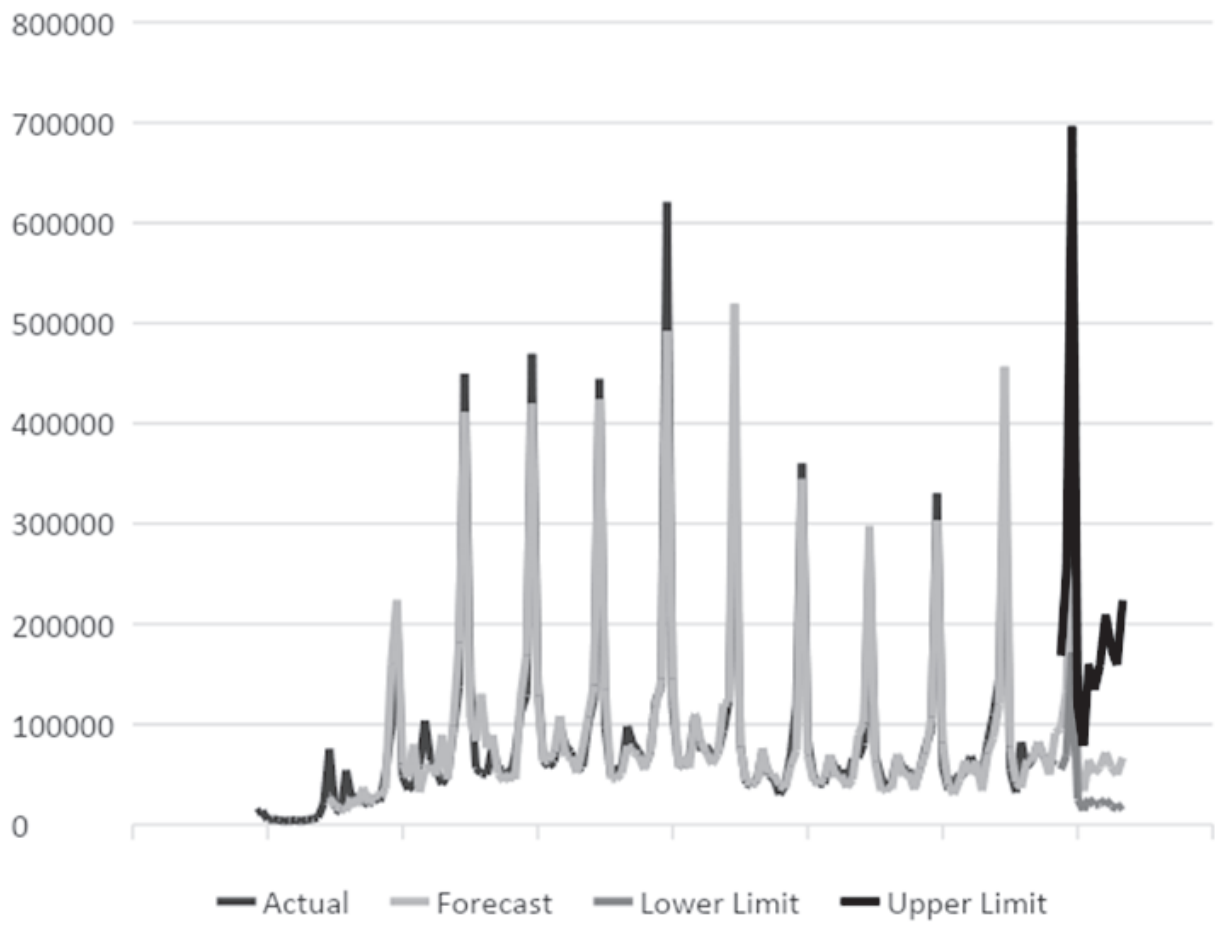

Fig. 4. Actual data and forecast line using the SARIMA model $(2,1,0)(1,1,0)_{12}$ Source: Actual Data: Ubisoft Italy; Forecast SARIMA $(2,1,0)(1,1,0)_{12}$ : GRETL Soft.

For this analysis on ETS methodology, a dampening coefficient has been used, which means that although trend damping is more complex than other ETS methods, the forecast result is efficient avoiding any kind of overshooting problem [Gardner, 
McKenzie 1988]. Whereas the Holt-Winters method tends to overestimate the forecast line, Gardner and McKenzie [1985] demonstrated that $\delta$ gives more control on trend extrapolation. In fact if $0<\delta<1$ it is normally distributed with a mean of 0 and a variance of $\sigma^{2} /\left(1-\delta^{2}\right)$. The process for the SARIMA model's identification was performed using traditional criteria such as AIC [Akaike 1974], BIC [Schwarz 1978], and HQC [Hannan, Quinn 1979] together with the loss functions MAPE, SMAPE and RMSE. For this specific case, two models were compared, SARIMA $(0,1,1)(0,1,1)_{12}$ and SARIMA $(2,1,0)(1,1,0)_{12}$. The model used for the prediction was SARIMA $(2,1,0)(1,1,0)_{12}$, where in spite of a very small increase in the above mentioned criteria, the measure of loss functions are better than SARIMA $(0,1,1)$ $(0,1,1)_{12}$. Furthermore, the result for annual data as an out-of-sample forecast is showing a remarkable improvement using the seasonal ARIMA model compared with exponential smoothing with damped trend. Based on the analysis, the SARIMA $(2,1,0)(1,1,0)_{12}$ model is the most suitable model for forecasting the console games, see Figure 4.

\section{Concluding remarks}

The complexity of this market is mainly due to manufacturer's decision. For this article, the forecast estimation is based on the physical consoles, including handhelds. The estimation process is absolutely crucial and once the estimation is completed, the manufacturer could use the estimation to accept or reject the financial risk. Additionally, the forecast demand could use this value to predict several items such as accessories, sequel games and other complements. Furthermore, consoles and handhelds are embracing both the physical and digital markets, giving a greater continuity for the software manufacturers. In this scenario, a good forecast representation is fundamental for various reasons, especially for consumer needs. Moreover, the demand forecast is also affected by the games genres and by the game-players attitude, and additionally, by some external conditions. This is confirmed by the survey led by ESA (Entertainment Software Association) where the average age of players in 2017 is 35 years old and in subsequent years is reducing year over year, in the meantime the percentage of female gamers is increasing year on year. Exponential smoothing and the SARIMA model are just a part of several techniques like hybrid models, the non-linear artificial neural network and others. They are still solid, reliable and very user-friendly due to many software applications for PCs. In this article two models were compared, exponential smoothing with damped trend and the SARIMA model. The criteria of evaluating these models was the loss function represented by MAPE, sMAPE and RMSE in Table 3. In terms of performance, the smallest values concerning these measures represent the best choice between the models studied, and the preferred option for this time series is SARIMA $(2,1,0)(1,1,0)_{12}$. Therefore the SARIMA model is the most reliable and relevant model for this analysis. 


\section{Bibliography}

Akaike H., 1974, A new look at the statistical model identification, IEEE Transactions on Automatic Control, 19(6), pp. 716-723.

Anvari S., Tuna S., Canci M., Turkay M., 2016, Automated Box-Jenkins forecasting tool with an application for passenger demand in urban rail systems, Journal of Advanced Transportation, (50), pp. 25-49.

Armstrong J.S., 1985, Long-Range Forecasting: From Crystal Ball to Computer, 2nd. ed., Wiley.

Assimakopoulos V., Makridakis S., Spiliotis E., 2018, Statistical and Machine Learning forecasting methods: Concerns and ways forward, Alejandro Raul Hernandez Montoya, Universidad Veracruzana, Mexico Plos One 13(3).

Barrow D., Kourentzes N., 2016, Distributions of forecasting errors of forecast combinations: Implications for inventory management, International Journal of Production Economics, 177, pp. 24-33.

Box G.E.P., Jenkins G.M., Reinsel G.C., 1994, Time Series Analysis; Forecasting and Control, 3rd Edition, Prentice Hall, Englewood Cliff, New Jersey.

Brown R.G., 1959, Statistical Forecasting for Inventory Control, McGraw-Hill, New York.

Entertainment Software Association Year Report (2017-2018).

Fildes R., 1989, Evaluation of aggregate and individual forecast method selection rules, Management Science, 35(9), pp. 1056-1065.

Fildes R., Lusk E.J., 1984, The choice of a forecasting model, Omega, 12(5), pp. 427-435.

Gardner E.S., Jr., 2006, Exponential smoothing: The state-of-the-art-Part II, International Journal of Forecasting, 22(4), pp. 637-666.

Gardner E.S., Jr., McKenzie E., 1985, Forecasting trends in time series, Management Science, 31, pp. 1237-1246.

Gardner E.S., Jr., McKenzie E., 1988, Model identification in exponential smoothing, The Journal of the Operational Research Society, Vol. 39(9), pp. 863-867.

Gardner E.S., Jr., McKenzie E., 2011, Why the Damped Trend works, Journal of the Operational Research Society, 62(6), pp. 1177-1180.

Handanhal V.R., 2013, Determining the optimal values of exponential smoothing constants - does solver really work?, American Journal of Business Education, 6 (3).

Hannan E.J., Quinn B.G., 1979, The determination of the order of an autoregression, Journal of the Royal Statistical Society, Series B, 41, pp. 190-195.

Hibon M., Makridakis S., 1979, Accuracy of forecasting, Journal of the Royal Statistical Society Series A (General), 142(2).

Hyndman R.J., Koelher A.B., Ord J.K., Snyder R.D., 2008, Forecasting with Exponential Smoothing, The State Space Approach, Springer Series in Statistics.

Hyndman R.J., Koehler A.B., Snyder R.D., Grose S., 2002, A state space framework for automatic forecasting using exponential smoothing methods, International Journal of Forecasting, 18(3), pp. 439-454.

Holt C.C., 1957, Forecasting Seasonals and Trends by Exponentially Weighted Moving Averages, ONR Memorandum, Vol. 52, Carnegie Institute of Technology, Pittsburgh.

International Game Developer Association, Developer Satisfaction Survey 2017.

Kalman R.E., 1960, A New Approach to Linear Filtering and Prediction Problems, Research Institute for Advanced Study, Baltimore, Maryland.

Koehler A.B., Ord J.K., Snyder R.D., 2001, Forecasting models and prediction intervals for the Multiplicative Holt-Winters Method, International Journal of Forecasting, 17(2), pp. 269-287.

Lutkepohl H., Xu F., 2009, The role of the log transformation in forecasting economic variables, EUI Working Papers, Max Weber Programme. 
Gossel W., Laehne R., 2013, Applications of time series analysis in geosciences: An overview of methods and sample applications, Hydrology and Earth System Sciences Discussions, 10(10), pp. 12793-12827.

Lattyak W.J., Stokes H.H., 2011, Exponential Smoothing Forecasting Using SCAB34S and SCA WorkBench, Department of Economics University of Illinois, Chicago.

Newzoo Global Market Report, 2018, Trends, Insights, and Projections toward 2021.

Office for National Statistics, 2008, From Holt-Winters to ARIMA Modelling: Measuring the Impact on Forecasting Errors for Components of Quarterly Estimates of Public Service Output, UK Centre for the Measurement of Government Activity.

Sbrana G., 2012, Damped trend exponential smoothing: Prediction and control, Journal of Quantitative Economics, 10(2), pp. 152-192.

Schwarz G.E., 1978, Estimating the dimension of a model, Annals of Statistics, 6(2), pp. 461-464.

Winters P.R., 1960, Forecasting sales by exponentially weighted moving averages, Management Science, 6, pp. 324-342.

Zhang G.P., 2001, Time series forecasting using a hybrid ARIMA and neural network model, Neurocomputing, 50, pp. 159-175.

\section{PROGNOZOWANIE SPRZEDAŻY GIER KONSOLOWYCH NA RYNEK WLOSKI}

Streszczenie: Analiza szeregów czasowych może być bardzo przydatna w określaniu ogólnej ewolucji i zachowania dynamiki rynku gier wideo. Metody mogą być stosowane do poszukiwania rozwiązań problemów związanych z prognozowaniem szeregów czasowych, niezależnie od sektora aplikacji. W prezentowanym artykule omówiono aplikacyjne aspekty zastosowania szeregów czasowych do prognozowania sprzedaży gier konsolowych na rynek włoski. Zastosowano i oceniono użyteczność dwóch technik jednoczynnikowych, takich jak wygładzanie wykładnicze i technika SARIMA. Celem badania było wykorzystanie możliwości tych metod statystycznych do porównania wyników i wybrania najdokładniejszego modelu na podstawie oceny ex post. Na podstawie danych miesięcznych (od listopada 2005 r. do września 2017 r.) wskazano najbardziej odpowiedni model o najmniejszej wartości miar dokładności (MAPE, sMAPE, RMSE) dla obserwacji poza próbą dotyczących okresu październik $2017 \mathrm{r}$. - wrzesień 2018 r. Implem4entację modeli przeprowadzono z wykorzystaniem Forecast PRO i Gretl. Szeregi czasowe dotyczyły wielkości sprzedaży pierwszych producentów konsol i urządzeń przenośnych (Microsoft, Sony i Nintendo).

Słowa kluczowe: wygładzanie wykładnicze, SARIMA, prognoza, gry wideo. 